\title{
Determination of Metals in Brazilian Ready-to-Drink Beverages (Ice Drinks) by Inductively Coupled Plasma Optical Emission Spectrometry
}

\author{
Roberta E.S. Froes-Silva ${ }^{a *}$, Waldomiro B. Neto ${ }^{b}$, Clésia C. Nascente ${ }^{c}$, and José B.B. da Silva ${ }^{c}$ \\ ${ }^{a}$ Department of Chemistry, Federal University of Ouro Preto, Ouro Preto, MG-Brazil, 35400-000 \\ bInstitute of Chemistry, Federal University of Uberlandia, \\ Uberlandia, MG-Brazil 38400-902 \\ 'Department of Chemistry, Federal University of Minas Gerais, Belo Horizonte, MG-Brazil, 31270-901
}

\section{INTRODUCTION}

Alcoholic ready-to-drink beverages (RTDs) are also known as FABs (flavored alcoholic beverages).

These drinks were introduced into the world market in the mid-1990s. They usually consist of some kind of distilled beverage (vodka, rum, spirits, alcohol of cereals) and fruit juices or soft drinks. Their alcoholic content ranges from 4 to $7 \%$ and are available in several flavors and brands (1). The most common RTDs are the alcopops or alcoholic sodas (2). Research has shown that the consumption of drinks such as alcopops is the fastest growing market in the world (3) with the consumers usually ranging in age from 18 to 25 years.

Many analytical methods have been used for determining inorganic elements in alcoholic beverages. Anodic stripping voltammetry was used by Barbeira et al. (4) to determine trace amounts of $\mathrm{Zn}, \mathrm{Pb}$, and $\mathrm{Cu}$ in sugar cane spirits. Canuto et al. (5) employed electrothermal atomic absorption spetrometry (ETAAS) and ruthenium as the permanent modifier to determine $\mathrm{Sb}$ and $\mathrm{Cr}$ in 53 samples of sugar cane spirits. Flame atomic absorption spectrometry and hydride generation (FAAS and HGFAAS) were used to determine As, $\mathrm{Cd}, \mathrm{Pb}, \mathrm{Cu}, \mathrm{Zn}, \mathrm{Fe}$, and $\mathrm{Mn}$ in 31 Serbian old plum brandies (6). Inductively coupled plasma optical emission spectrometry (ICP-OES) was employed (7) for the analysis

\footnotetext{
*Corresponding author.

E-mail: robertafroes@botmail.com,

Tel: (55) $313559-1233$
}

\section{ABSTRACT}

The consumption of ready-todrink (RTD) beverages has been constantly increasing. However, the control of toxic and essential elements for this type of beverage requires the employment of adequate analytical methods. Inductively coupled plasma optical emission spectrometry (ICPOES) was employed to investigate toxic and essential elements in RTD beverages. This kind of beverage has an alcoholic composition ranging from 4 to $7 \%$ and, therefore, optimization of the plasma conditions is necessary for sample analysis. Robust conditions were obtained when the power applied was maintained at $1.4 \mathrm{~kW}$. Sample and nebulization gas flow rates used were $1.0 \mathrm{~mL} \mathrm{~min}^{-1}$ and $0.6 \mathrm{~L} \mathrm{~min}^{-1}$, respectively. A calibration curve was plotted at $6 \%$ (v/v) ethanol and $2 \%$ (v/v) $\mathrm{HNO}_{3}$. Satisfactory LOD and LOQ values were obtained for $\mathrm{Al}, \mathrm{Ba}, \mathrm{Ca}, \mathrm{Cd}$, $\mathrm{Cr}, \mathrm{Cu}, \mathrm{Fe}, \mathrm{K}, \mathrm{Mg}, \mathrm{Mn}, \mathrm{Na}, \mathrm{Ni}, \mathrm{Pb}$, $\mathrm{Sn}$, and $\mathrm{Zn}$. The recoveries were acceptable and ranged from 80 to $120 \%$. Exploratory analysis was performed by utilizing a Hierarchical Cluster Analysis (HCA) and Principal Component Analysis (PCA) which enabled classification of the samples based on the brand and type of distilled beverage contained in the RTD.

of several alcoholic beverages with an alcoholic content ranging from 40 and 55\%. They employed two statistical methods (Canonical Discriminant Analysis - CDA and Classification Binary Trees - CBT) to evaluate the parameters for differ- entiating the beverage samples. Fernandes et al. (8) used ICP-OES to determine 15 elements in sugar cane spirits through exploratory analysis. They only verified the differentiation between industrial and homemade spirits. Jurado et al. (9), who employed ICP-OES and several pattern recognition methods for sample classification, investigated the chemical composition of Spanish aniseed drinks. Souza et al. (10) used direct infusion electrospray ionization mass spectrometry in the negative ion mode to differentiate spirit samples. They found four groups which were characterized by the type of wood casks used.

RTD analysis employing multielemental techniques such as ICPOES allows the control of toxic and essential elements in such beverages. Adjustment of the ICP conditions permits direct analysis of the alcoholic matrix and thus prevents extinction of the plasma.

The data obtained using this method can be interpreted by means of the chemometric methods of exploratory analysis such as Hierarchical Clusters Analysis (HCA) and Principal Components Analysis (PCA). These methods allow the classification and separation of the samples and indicate the elements responsible for sample distinction $(11,12)$. This work presents the optimization of the experimental conditions and parameters of merit for RTD analysis by ICPOES for the quantification of 15 elements in 30 samples. The exploratory analysis of the data obtained provided a better visualization and therefore allowed sample separation into different groups. 


\section{EXPERIMENTAL}

\section{Instrumentation}

A PerkinElmer Optima ${ }^{\mathrm{TM}} 2000$ DV ICP-OES with radial and axial configuration was employed for all measurements (PerkinElmer, Inc., Shelton, CT, USA). The instrument was equipped with a $40 \mathrm{MHz}$ radio frequency source, Echelle grating (79 lines $\mathrm{nm}^{-1}$ ), solid state detector, plasma torch with a $2.0 \mathrm{~mm}$ internal diameter injection, and a crossflow nebulizer coupled to a doublepass Scott-type spray chamber. An interface (shear gas) introducing a high air flow perpendicular to the torch was used to remove the low temperature at the end of the plasma. An autosampler 90 Plus (PerkinElmer) system was used for sample introduction. The instrumental operating conditions, elements, and the respective wavelengths used are listed in Table I.

Solutions, Reagents, and Samples

Solutions containing $6 \%(\mathrm{v} / \mathrm{v})$ ethanol were prepared in order to simulate the original alcoholic concentration found in commercial RTDs. Reference solutions of $\mathrm{Al}, \mathrm{Ba}$,
$\mathrm{Ca}, \mathrm{Cd}, \mathrm{Cr}, \mathrm{Cu}, \mathrm{Fe}, \mathrm{K}, \mathrm{Mg}, \mathrm{Mn}, \mathrm{Na}$, $\mathrm{Ni}, \mathrm{Pb}, \mathrm{Sn}$, and $\mathrm{Zn}\left(1000 \mathrm{mg} \mathrm{L}^{-1}\right)$ of high analytical purity (CertiPUR ${ }^{\circledR}$ ICP Standard, Merck, Germany) were used to prepare the multielemental solutions containing 100 $\mathrm{mg} \mathrm{L}^{-1}$ of the analytes in $2 \%$ (v/v) $\mathrm{HNO}_{3}$ (VETEC, São Paulo, Brazil) $70 \%)$. These solutions were employed for the construction of matrix matched calibration curves and test solutions in $(6 \%, v / v)$ of deionized water obtained with a Milli-Q ${ }^{\circledR}$ system (Millipore Corporation, Bedford, MA, USA) was used to prepare all solutions. The commercial samples of RTDs were diluted $(1: 1, \mathrm{v} / \mathrm{v})$ with $2 \% \mathrm{HNO}_{3}$ (v/v) and introduced into the autosampler. For $\mathrm{Na}, \mathrm{Ca}$, and $\mathrm{K}$ determination, a dilution of (1:10, v/v) was used for all samples. Table II lists the RTD samples analyzed and their specifications.

\section{Procedure}

\section{Optimization of ICP-OES Conditions}

A univariate optimization for the ICP-OES conditions was realized by measurement of the $\mathrm{Mg}$ (II)/Mg(I) ratio as the robustness criterion.
The applied power was fixed at $1.4 \mathrm{~kW}$ and the nebulization gas flow rate was varied from 0.4 to 1.1 L min ${ }^{-1}$. All measurements were made using axial and radial view.

\section{Analytical Figures of Merit}

The analytical figures of merit were based on experiments as proposed in the literature $(13,14)$. The short-term stability was determined by performing 15 consecutive measurements of the intensity emission at the $\mathrm{Mg}$ (II) $280.265 \mathrm{~nm}$ line. Long-term stability was evaluated by monitoring the emission line for a period of two hours where 8-minute measurements with an interval of 15 minutes were made.

The signal-to-background ratio (SBR), background equivalent concentration (BEC), limit of detection (LOD), and limit of quantification (LOQ) were calculated according to the IUPAC recommendations as follows (14):

$$
\mathrm{SBR}=\frac{\left(\mathrm{I}_{\mathrm{rs}}-\mathrm{I}_{\mathrm{Blank}}\right)}{\mathrm{I}_{\text {Blank }}} \quad \mathrm{BEC}=\frac{\mathrm{C}_{\mathrm{rs}}}{\mathrm{SBR}}
$$

TABLE I

ICP-OES Operating Parameters

\begin{tabular}{ll}
\hline Parameters & \\
\hline RF Power & $1.4 \mathrm{~kW}$ \\
Nebulization gas flow & $0.4-1.1 \mathrm{~L} \mathrm{~min}^{-1 \mathrm{a}}$ \\
Sample flow & $1.0 \mathrm{~mL} \mathrm{~min}-1$ \\
Auxiliary gas flow & $0.2 \mathrm{~L} \mathrm{~min}^{-1}$ \\
Plasma gas flow & $15 \mathrm{~L} \mathrm{~min}^{-1}$ \\
Injector tube diameter & $2.0 \mathrm{~nm}$ \\
Interface & $\mathrm{Shear}$ gas \\
Emission lines $(\lambda / \mathrm{nm})$ & $\mathrm{Al}(\mathrm{I}=396.15), \mathrm{Ba}(\mathrm{II}=455.403)$, \\
& $\mathrm{Ca}(\mathrm{I}=317.93), \mathrm{Cu}(\mathrm{I}=324.75)$, \\
& $\mathrm{Fe}(\mathrm{II}=238.2), \mathrm{K}(\mathrm{I}=766.49)$, \\
& $\mathrm{Na}(\mathrm{I}=589.59), \mathrm{Mg}(\mathrm{I}=285.21)$, \\
& $\mathrm{Mn}(\mathrm{II}=257.61), \mathrm{Sn}(\mathrm{II}=189.99)$ \\
\hline
\end{tabular}

${ }^{\text {a }}$ Optimized values during the experiments.

$\mathrm{I}=$ Atomic line $\quad \mathrm{II}=$ Ionic line
TABLE II Description of Analyzed Ready-To-Drink Samples

\begin{tabular}{ll|cl}
\hline Brand & Description & Brand & Description \\
\hline A1 & Alcohol of cereals & D1 & vodka \\
A2 & Alcohol of cereals & D2 & vodka \\
B1 & Vodka & E1 & Sugar cane spirits \\
B2 & Vodka & E2 & Sugar cane spirits \\
B3 & Vodka & E3 & Sugar cane spirits \\
B4 & Vodka & E4 & Sugar cane spirits \\
B5 & Vodka & F1 & vodka \\
B6 & Vodka & F2 & vodka \\
B7 & Vodka & F3 & vodka \\
B8 & Vodka & F4 & vodka \\
C1 & Vodka & G1 & Rum \\
C2 & Vodka & G2 & Rum \\
C3 & Vodka & H1 & Sugar cane spirits \\
C4 & Vodka & H2 & Sugar cane spirits \\
C5 & Vodka & I1 & Vodka \\
\hline
\end{tabular}


LOD $=\frac{3 \times \text { RSD }_{\text {Blank }} \times \text { BEC }}{100}$

LOQ $=\frac{10 \times \mathrm{RSD}_{\text {Blank }} \times \mathrm{BEC}}{100}$

where $\mathrm{I}_{\mathrm{rs}}=$ Intensity of reference solution; $\mathrm{I}_{\mathrm{Blank}}=$ Intensity of blank solution; $\mathrm{C}_{\mathrm{rs}}=$ Concentration of reference solution; $\mathrm{RSD}=$ relative standard deviation of 10 measurements of the blank solution.

The accuracy of the method was evaluated with an RTD solution of 0.5 and $2.0 \mathrm{mg} \mathrm{L}^{-1}$ of metals added. The exploratory analyses by HCA and PCA were performed by running the PLS Toolbox 3.0 for Matlab® (Mathworks, Inc., USA) (15). These methods were used to evaluate the similarity between the RTD samples by forming different groups according to types.

\section{RESULTS AND DISCUSSION}

\section{Optimization of ICP-OES Conditions}

The influence of the nebulization gas flow rate over plasma robustness was evaluated using the
$\mathrm{Mg}$ (II)/Mg(I) ratio. The term robustness represents the efficiency of energy transfer when the excitation and ionization conditions of the plasma are changed $(14,16)$. In this experiment, the applied power was fixed at $1.4 \mathrm{~kW}$ and the nebulization gas flow varied from 0.4 1.1 $\mathrm{L} \mathrm{min}^{-1}$. The highest value of the $\mathrm{Mg}(\mathrm{II}) / \mathrm{Mg}(\mathrm{I})$ ratio was obtained with a $0.6 \mathrm{~L} \mathrm{~min}^{-1}$ gas flow rate at axial view (Figure 1 ). With radial view, the best value for $\mathrm{Mg}$ (II)/ $\mathrm{Mg}$ (I) was obtained at the $0.9 \mathrm{~L} \mathrm{~min}^{-1}$ gas flow rate. The use of low gas flow values increases the plasma robustness, but values of less than $0.5 \mathrm{~L}$ $\mathrm{min}^{-1}$ must be avoided because the residence time of the analyte is high and self-absorption can occur $(17,18)$. The robustness condition (sample flow rate $1.0 \mathrm{~mL} \mathrm{~min}^{-1} ; \mathrm{RF}$ power $1.4 \mathrm{~kW}$; nebulization gas flow rate $0.6 \mathrm{~L} \mathrm{~min}^{-1}$; axial view) was adopted in later studies.

\section{Analytical Figures of Merit}

For axial and radial view, the short-term stability afforded an RSD of 1.03 and $1.10 \%$, respectively; the long-term stability was $0.91 \%$ and $1.7 \%$. Considering that in an aqueous matrix other authors (14)

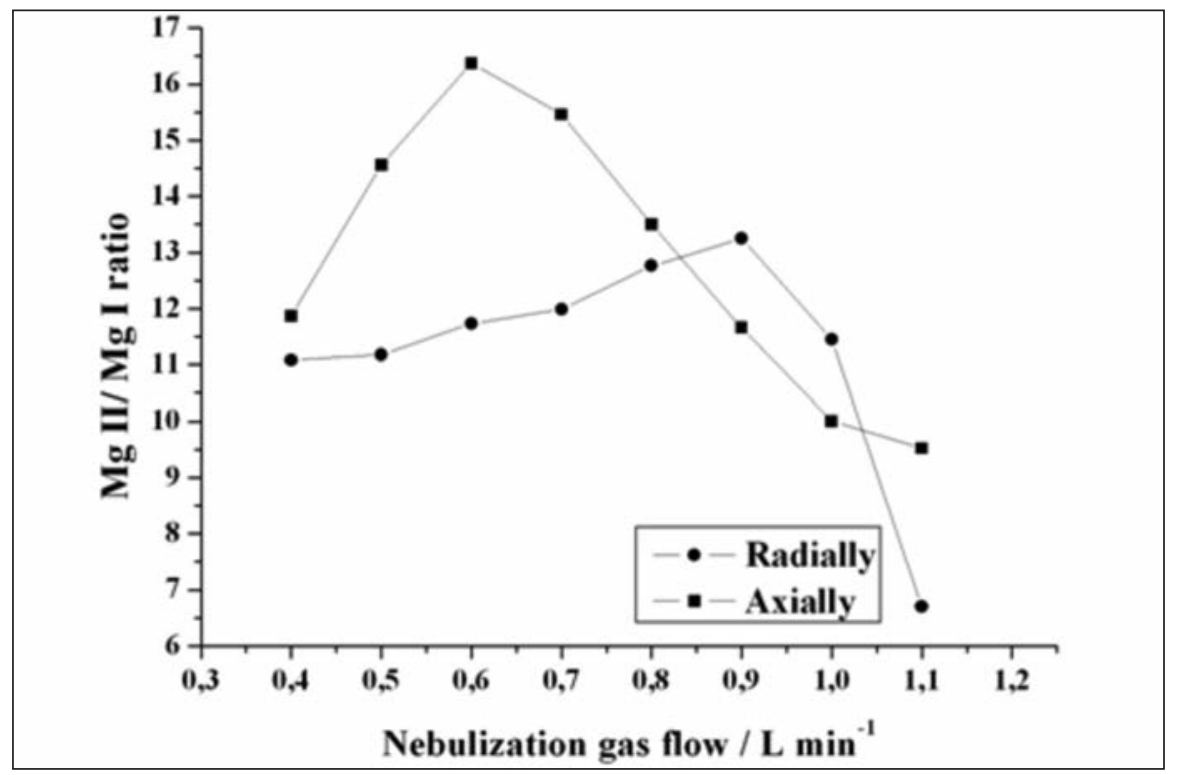

Fig. 1. Effect of nebulization gas flow rate on $\mathrm{Mg}(\mathrm{II}) / \mathrm{Mg}(\mathrm{I})$ ratio (RF power $1.4 \mathrm{~kW}$ ).

obtained an RSD of 0.7 and 1.5 for short- and long-term stability, respectively, the RSD values obtained in this study were satisfactory.

The analytical figures of merit and the quantification results for 30 RTD samples (SBR, BEC, LOD, LOQ, concentration range, and recovery) are listed in Table III. Good values for the SBR, BEC, LOD, and LOQ were obtained for most of the investigated analytical lines. The recoveries observed were satisfactory with a maximum recovery value between 80 to $120 \%$ of the expected value (19). The concentration range of the samples was less than the LOQ for $\mathrm{Cr}$ and $\mathrm{Mn}$. For $\mathrm{Na}$ (which is one of the elements whose levels can become dangerous for the consumer), the values obtained ranged from 11.58 to $276.8 \mathrm{mg} \mathrm{L}^{-1}$. The elevated values obtained for $\mathrm{Na}$ can be associated with the addition of con- servators and/or sweeteners with sodium.

\section{Exploratory Analysis}

Hierarchical Cluster Analysis (HCA)

HCA was used in order to establish possible similarities between the samples. The samples were categorized into four groups and are presented in Figure 2. The first two groups include samples with a vodka base (C4, C1, B8, B7, B3, B6, B5) and a sugar cane spirits base (E2, E1, E4); the third group contains samples with an alcohol of cereals base (A2, A1, I1); and the fourth group are samples with a sugar cane spirits base (H2, H1). The rum samples (G1 and G2) are included in the first group due similarities in their composition. Brand $\mathrm{C}$ are samples contained in different packaging: $\mathrm{C} 1$ and $\mathrm{C} 4$ in glass bottles and $\mathrm{C} 2, \mathrm{C} 3$, and $\mathrm{C} 5$ in cans. 
TABLE III

Analytical Figures of Merit for Ready-to-Drink Analysis by ICP-OES: BEC, SBR, LOD, LOQ, Concentration Range, and Recovery

\begin{tabular}{|c|c|c|c|c|c|c|}
\hline Element & SBR & BEC & $\begin{array}{l}\text { LOD } \\
\left(\mu \mathrm{g} \mathrm{L}^{-1}\right)\end{array}$ & $\begin{array}{l}\mathrm{LOQ} \\
\left(\mu \mathrm{g} \mathrm{L}^{-1}\right)\end{array}$ & $\begin{array}{l}\text { Conentration } \\
\text { Range }\left(\mu \mathrm{g} \mathrm{L}^{-1}\right)\end{array}$ & $\begin{array}{l}\text { Recovery } \\
(\%)(n=3)\end{array}$ \\
\hline $\mathrm{Al}(\mathrm{I})$ & 603.6 & 0.0083 & 6.8 & 22.8 & $40-230$ & 104.2 \\
\hline $\mathrm{Ba}$ (II) & 79.9 & 0.03 & 4.3 & 14.3 & $<$ LOQ - 60 & 110.3 \\
\hline $\mathrm{Ca}(\mathrm{I})$ & 17 & 0.29 & 120.3 & 401.1 & $610-20600$ & 103.9 \\
\hline $\mathrm{Cd}$ (II) & 25566.5 & 0.0002 & 0.4 & 1.3 & $2-8$ & 103.1 \\
\hline $\mathrm{Cr}$ (II) & 15273.4 & 0.0003 & 0.2 & 0.5 & $<$ LOQ & 116.2 \\
\hline $\mathrm{Cu}(\mathrm{I})$ & 4165.1 & 0.001 & 0.2 & 0.7 & $4-48$ & 111.3 \\
\hline $\mathrm{Fe}$ (II) & 340.6 & 0.015 & 0.6 & 1.9 & $40-510$ & 108.6 \\
\hline $\mathrm{K}(\mathrm{I})$ & 758.6 & 0.0066 & 2.0 & 6.9 & $1200-112000$ & 93.6 \\
\hline $\operatorname{Mg}(\mathrm{I})$ & 351.8 & 0.014 & 6.3 & 21.0 & $40-4700$ & 109.8 \\
\hline Mn (II) & 869.1 & 0.0058 & 0.3 & 0.96 & $<$ LOQ & 105.6 \\
\hline $\mathrm{Na}(\mathrm{I})$ & 13165.8 & 0.0004 & 3.7 & 12.3 & $11580-276800$ & 91.6 \\
\hline $\mathrm{Ni}$ (II) & 489.1 & 0.01 & 1.7 & 5.6 & $20-120$ & 99.4 \\
\hline $\mathrm{Pb}$ (II) & 3042.6 & 0.002 & 3.6 & 12.4 & $<$ LOQ-24 & 115.6 \\
\hline Sn (II) & 262.3 & 0.019 & 11.7 & 39.1 & $40-500$ & 96 \\
\hline $\mathrm{Zn}$ (II) & 1893.1 & 0.003 & 0.3 & 1.03 & $3-10$ & 110.5 \\
\hline
\end{tabular}

SBR $=$ Signal-to-background ratio

$\mathrm{BEC}=$ Background equivalent concentration

LOD $=$ Limit of detection

LOQ $=$ Limit of quantification

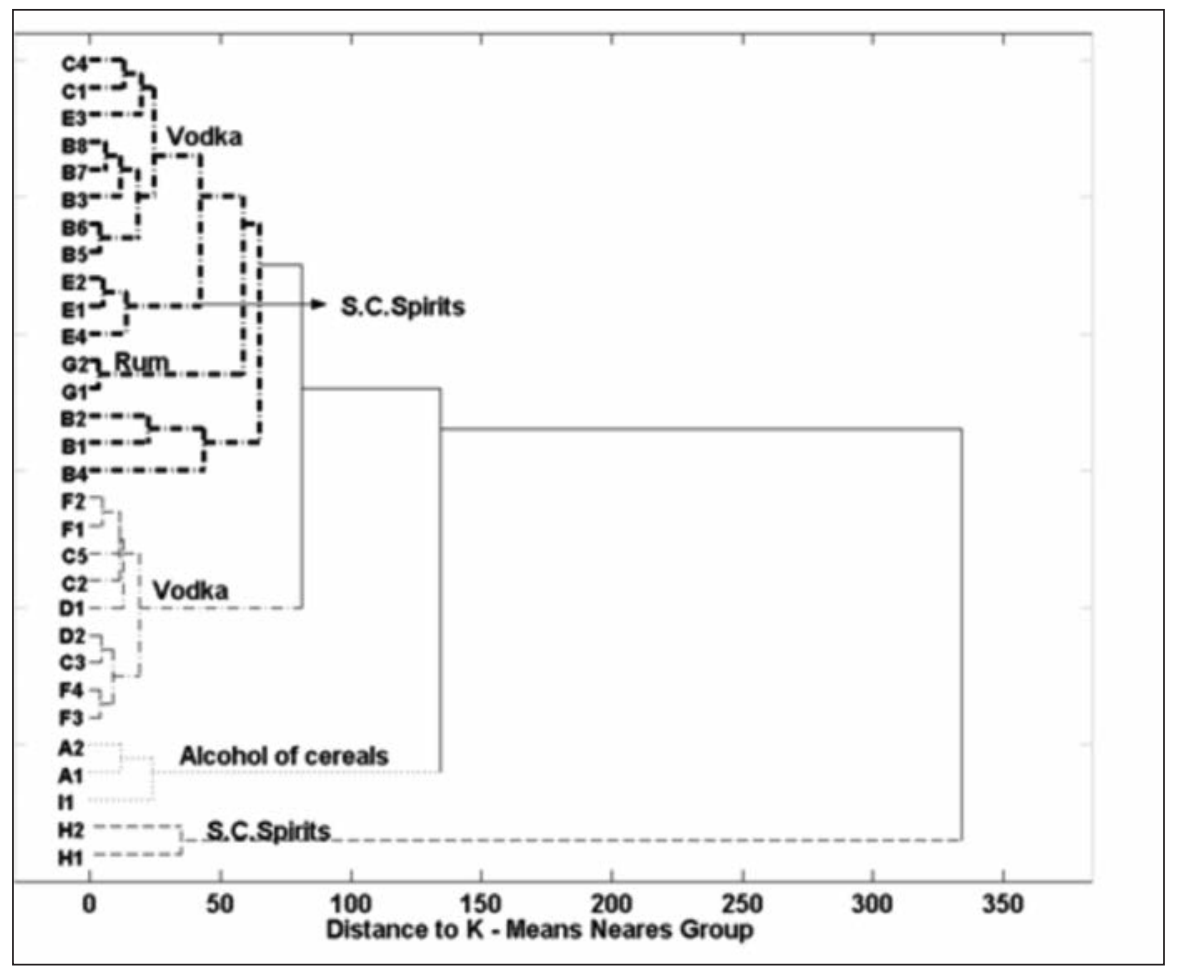

Fig. 2. Dendrogram of ready-to-drink beverages..
Principal Components Analysis (PCA)

PCA involved the same separation procedure as HCA. A model using three principal components (PC) was built and explains 99.97\% of the total variance. The discriminant elements for PC1 and PC2 were $\mathrm{K}$ and $\mathrm{Na}$ (Figures $3 \mathrm{a}$ and $3 \mathrm{~b}$ ), while for PC3, it was $\mathrm{Ca}$ and $\mathrm{Mg}$ (Figure 3c). These discriminant elements explain the separation obtained in Figure 4, which shows the same separation as the dendrogram in Figure 2. The samples of sugar cane spirits were separated from the other beverages due to a higher $\mathrm{K}$ concentration and a lower $\mathrm{Na}$ concentration. On the other hand, a lower $\mathrm{K}$ concentration and a higher $\mathrm{Na}$ concentration differentiates the cereal alcohol samples from the other beverages. The vodka samples were at intermediary concentrations of $\mathrm{K}$ and $\mathrm{Na}$. In each class, the samples of the inferior region possess low concentrations of $\mathrm{Ca}$ and $\mathrm{Mg}$ and higher values of the same elements in the superior region.

\section{CONCLUSION}

Adjustment of the ICP-OES operating conditions allows for a working method for the direct analysis of ready-to-drink (RTD) samples. Good analytical figures of merit were obtained under these conditions and the analysis of 30 real RTD samples was performed. Evaluating the data with Hierarchical Cluster Analysis (HCA) and Principal Components Analysis (PCA) made it possible to identify the samples into groups and the discriminant elements for each group. ICP-OES in conjunction with the exploratory statistical methods of PCA and HCA has shown to be a useful tool in providing a simple, rapid, and accurate methodology for the differentiation of RTD samples. As the preliminary results also point out, this technique can therefore be used with confidence for effective quality control of beverages. 


\section{Atomic Mpectroscopy \\ $\bigcup$ Vol. 36(1), Jan.Feb. 2015}



Fig. 3(a). Variables plot of the ready-to-drink beverage samples labelled: PC1



Fig. 3(b). Variables plot of the ready-to-drink beverage samples labelled: PC2

\section{ACKNOWLEDGMENT}

The authors wish to thank the Ezequiel Dias Foundation (FUNED) for their donation of laboratory equipment for this research; the Coordenação de Aperfeiçoamento de Pessoal de Nível Superior (CAPES, Brazil), Conselho Nacional de Desenvolvimento Científico e
Tecnológico (CNPq) and the Fundação de Amparo à Pesquisa do Estado de Minas Gerais (Fapemig) for their financial support; and Dr. Jason G. Taylor (UFOP) for insightful discussions and for reviewing the manuscript for its English usage.

$\overline{\text { Receivbed August 19, } 2014 .}$

\section{REFERENCES}

1. SBRT - Serviço Brasileiro de Respostas Técnicas - Aditivos na fabricação de bebida alcoólica mista. Available in: http://www.sbrt.ibict.br

2. M. Wick, G. Gerarhd, E. Kuntsche, J. Rehm, and E. Grichting, Is alcopop consumption in Switzerland associated with riskier drinking patterns and more alcohol-related problems? Society for the Study of Addiction, 522-533 (2006).

3. ACNIELSEN - Tendências e análises, Available in:

www.acnielsen.com.br

4. P.J.S., Barbeira, L.H. Mazo, and N.R. Stradiotto, Analyst 120, 6, 1647 (1995).

5. M.H. Canuto, G. Helmuth, L. Siebald, G.M. Lima, and J.B.B. Silva, J. Anal. At. Spectrom. 18, 11, 1404 (2003).

6. M. Bonic, V. Tesevic, N. Nikicevic, J. Cvejic, S. Milosavljevic, V. Vajs, B. Mandic, I. Urosevic, M. Velickovic, and S. Jovanic, J. Serb. Chem. Soc. 78(7), 933 (2013).

7. R. Kokkinofta, P.V. Petrakis, T. Mavromoustakos, and C.R. Theocharis, J. of Agric. Food Chem. 51, 6233 (2003).

8. A.P. Fernandes, M.C. Santos, S.G. Lemos, M.M.C. Ferreira, A.R.A. Nogueira, and J.A. Nóbrega, Spectrochim. Acta Part B. 60, 717 (2005).

9. J.M. Jurado, A. Alcázar, F. Pablos, M.J. Martín, and A.G. González, Talanta 66, 1350 (2005).

10. P.P. Souza, H.G.L. Siebald, D.V. Augusti, W.B. Neto, V.M. Amorim, R.R. Catharino, M.N. Eberlin, and R. Augusti, J. Agric. Food Chem. 55, 2094, (2007).

11. D.L. Massart, B.G.M. Vandeginste, L.M.C. Buydens, S. De Jong, P.J. Lewin, and J. Smeyers-Verbeke, Handbook of Chemometrics and Qualimetrics: Part B Elsevier, Amsterdam, The Netherlands (1998).

12. R.E.S. Froes, W. Borges Neto, M.A. Beinner, C.C. Nascentes, and J.B.B. Silva, .Food Anal. Methods 3, 1 (2013). 


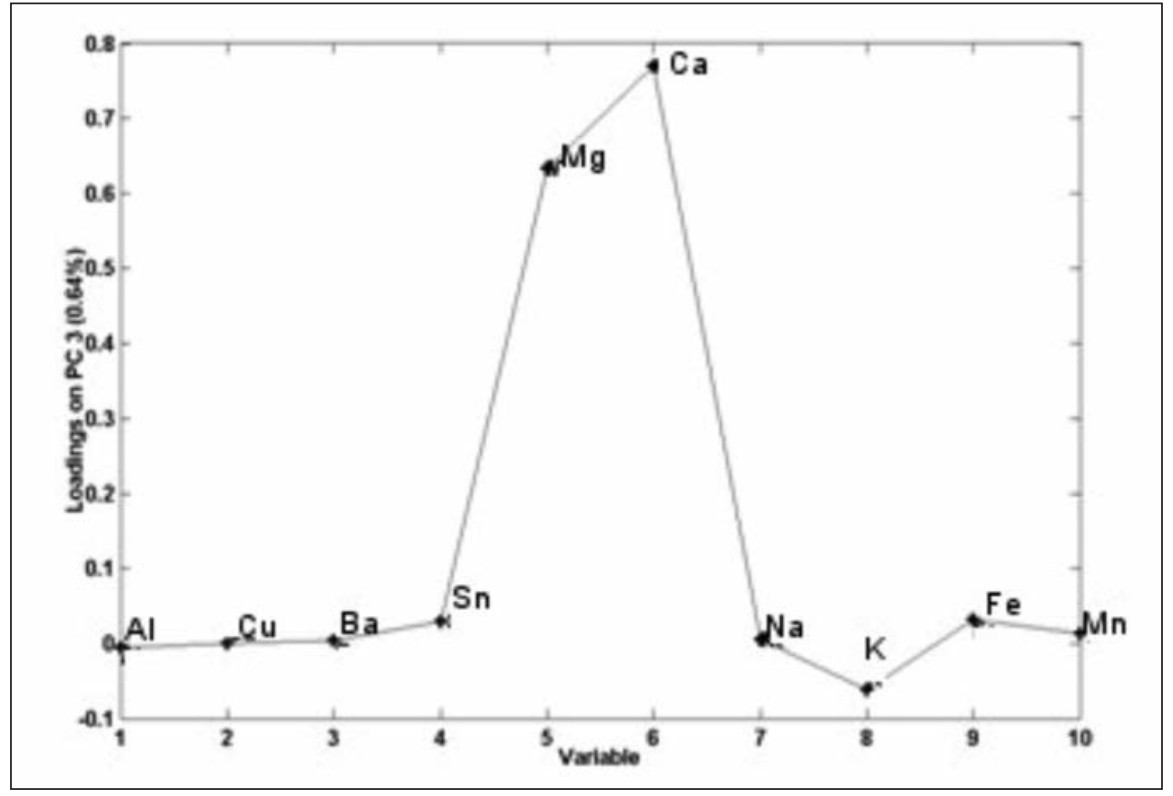

Fig. 3(c). Variables plot of the ready-to-drink beverage samples labelled: PC3
13. J.M. Mermet, and E. Poussel, Appl. Spectrosc. 49, 12-18 (1995).

14. F.V. Silva, C.L. Trevisan, C.S. Silva, A.R. Nogueira, J.A. Nóbrega. Spectrochim. Acta Part B, 57, 1905 (2002).

15. Matlab User's Guide, Mathworks, Inc., Naslick, MA, USA (1994).

16. J.M. Mermet Anal. Chim. Acta, 250, 85 (1991)

17. R.E.S. Froes, N.O.C. Silva, R.L.P. Naveira, J.C.J. Silva, V.S.T. Ciminelli, C.C. Windmoller, and J.B.B. Silva, At. Spectrom. 28(1), 8 (2007).

18. J.C.J. Silva, D.M. Santos, N. Baccan, S. Cadore, and J.A. Nóbrega, Microchem. 77, 185 (2004).

19. Environmental Protection Agency EPA. Guidance for Methods Development and Methods Validation for the RCRA Program SW-846 Methods (1992).

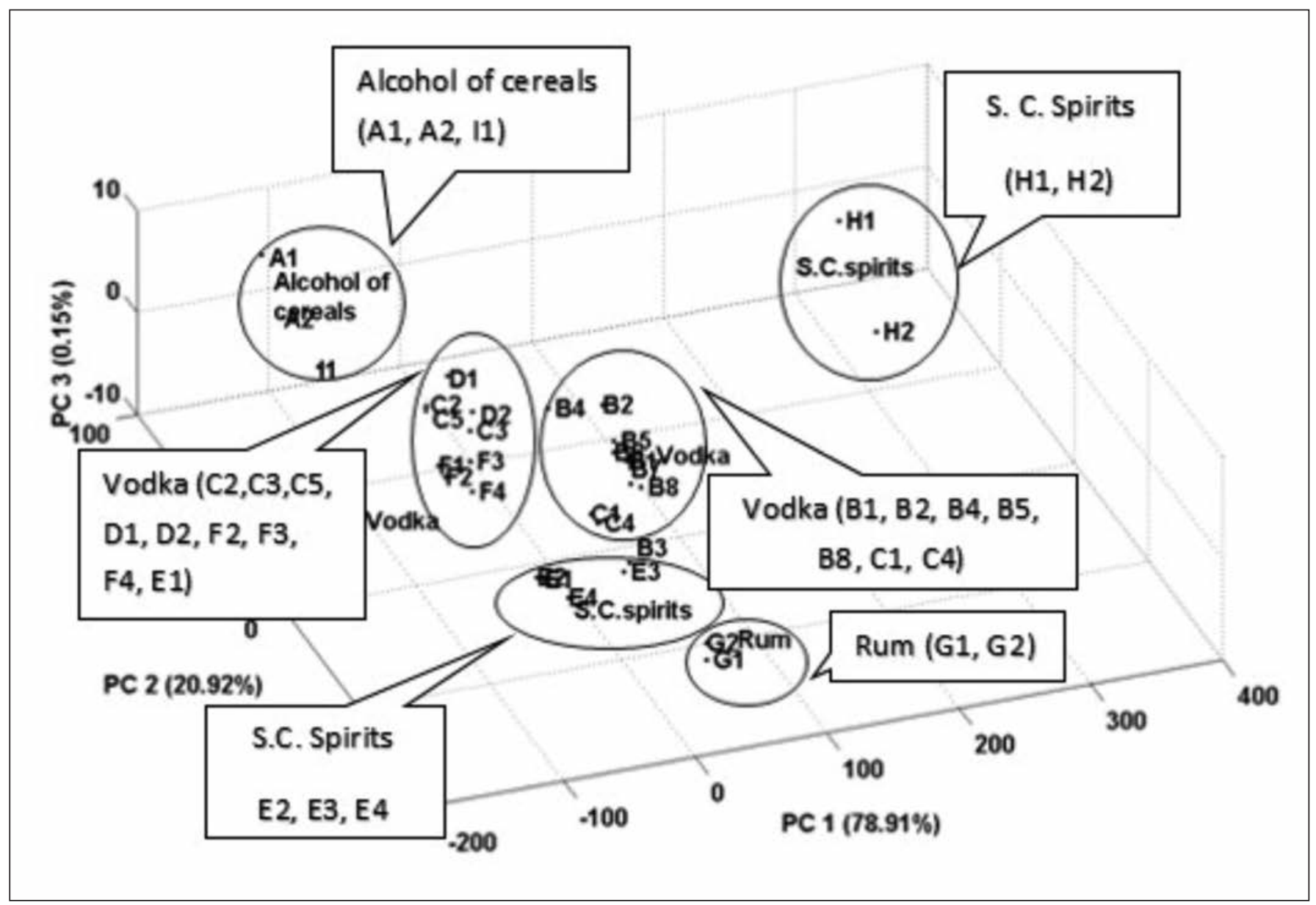

Fig. 4. Scores plot of the ready-to-drink beverage samples in the space of the first three PCs. 